Publié par :

Published by:

Publicación de la:

Édition électronique :

Electronic publishing:

Edición electrónica:

Disponible sur Internet :

Available on Internet

Disponible por Internet :
Faculté des sciences de l'administration

2325, rue de la Terrasse

Pavillon Palasis-Prince, Université Laval

Québec (Québec) Canada G1V 0A6

Tél. Ph. Tel. : $\quad$ (418) 656-3644

Télec. Fax : $\quad$ (418) 656-7047

Aline Guimont

Vice-décanat - Recherche et affaires académiques

Faculté des sciences de l'administration

http://www5.fsa.ulaval.ca/sgc/documentsdetravail rd@fsa.ulaval.ca

DOCUMENT DE TRAVAIL 2009-018

TRIP PACKING IN PETROL STATIONS REPLENISHMENT

Fayez F. BOCTOR

Jacques RENAUD

Fabien CORNILLIER

Version originale :

ISBN - 978-2-89524-344-1

Original manuscript:

Version original:

Série électronique mise à jour : $\quad$ 12-2009

On-line publication updated :

Seria electrónica, puesta al dia 


\title{
Trip packing in petrol stations replenishment ${ }^{1}$
}

\author{
Fayez F. Boctor ${ }^{2}$, Jacques Renaud ${ }^{3}$ and Fabien Cornillier ${ }^{4}$ \\ ${ }^{2,3}$ Centre interuniversitaire de recherche sur les réseaux d'entreprise, la logistique et le transport (CIRRELT) \\ Faculté des sciences de l'administration Université Laval \\ Québec, Canada G1K 7P4 \\ ${ }^{4}$ CENTRUM Católica, Lima, Peru.
}

\begin{abstract}
This paper considers a generalized version of the trip packing problem that we encountered as a sub-problem of the petrol stations replenishment problem. In this version we have to assign a number of trips to a fleet composed of a limited number of non-identical tank-trucks. Each trip has a specific duration, working time of vehicles is limited and the net revenue of each trip depends on the truck used. The paper provides a mathematical formulation of the problem and proposes some construction, improvement and neighbourhood search solution heuristics. A set of benchmark problem instances is created in a way that reflects real-life situations and used to analyse the performance of the proposed heuristics. A reallife case is also used to further assess the proposed heuristics.
\end{abstract}

Keywords: Vehicle scheduling, Trip packing, Mixed integer models, Heuristics.

\footnotetext{
${ }^{1}$ This research work was partially supported by the Canadian Natural Sciences and Engineering Research Council (NSERC) under grants OGP0172633 and OPG0036509. This support is gratefully acknowledged. We also express our gratitude to the referees for their valuable comments and suggestions.

${ }^{2}$ Corresponding author; email: Fayez.Boctor@fsa.ulaval.ca.

${ }^{3}$ Email: Jacques.Renaud@fsa.ulaval.ca.

${ }^{4}$ Email: fcornillier@pucp.edu.pr.
} 


\section{INTRODUCTION}

In this paper we address a new trip packing problem which arises as a sub problem of the petrol stations replenishment problem (PSRP) that will be called hereafter the generalized trip packing problem (GTPP). To solve the PSRP (see Cornillier et al. [1]), we start by designing a set of trips to deliver the petrol products needed or ordered by the petrol stations and then pack these trips into subsets such that each subset can be performed within a working day by one of the available trucks. The GTPP is defined by a limited number of non identical tank-trucks and a limited number of overtime hours allowed. The heterogeneous fleet implies that the revenue of a given trip depends on the truck used for the trip, and that some trips may not be feasible for a given truck due to the characteristics and capacity of the vehicle. The objective considered is to maximize the overall net revenue of operations which is the sum over all trips of net revenue minus the marginal cost of overtime hours required. The net revenue of a trip is its revenue minus the variable operating cost (fuel consumption and cost of driver regular hours) of the used truck. The fixed cost of trucks (depreciation and regular maintenance cost) is not taken into consideration as it is paid whether the truck is used or not. Some other objectives can be overseen. Mainly, three alternative objectives are considered: to maximize the total amount of products to deliver, to maximize overall net revenue per litre delivered, and to minimize the maximum overtime hours. However, in business the main and most used objective is to maximize overall net revenue.

To the best of our knowledge, the GTPP has never been addressed in the literature. A more simplified version of this problem, called hereafter the Simple Trip Packing Problem (STPP), has been mentioned in the literature dealing with the multi-trip vehicle routing problem (MTVRP). While some contributions try to solve the MTVRP as a whole (see Brandão and Mercer [2], [3]), most others solve the problem in two steps: first generate the set of routes to be used and then pack these trips (see Fleischmann [4], Taillard et al. [5] Golden et al. [6], Zhao [7], Petch and Salhi [8] and Olivera and Viera [9]).

STPP usually assumes that we have an unlimited number of identical trucks (unlimited homogeneous fleet), that all working hours are regular hours and that trip cost and revenue are the same whichever trucks are used. Consequently, the problem is reduced to the standard Bin Packing Problem (BPP). This explains why the contributions addressing the homogeneous fleet 
MTVRP solve the trip packing sub-problem as a bin packing problem. For a survey of the literature on bin packing problems see Coffman et al. [10].

Only Prins [11] considered the Multi-trip vehicle routing problem (MTVRP) with limited heterogeneous fleet. However he also solves the trip packing sub-problem as a bin packing problem using a straightforward adaptation of the first fit decreasing (FFD) heuristic. The objective considered is to minimize the number of used vehicles. Trips cost and revenue are not taken into consideration.

In contrast, in the GTPP, trips are packed into working days that have maximum regular and overtime working hours, trucks have different capacities and trip net revenues depend on the trucks used. This implies that solution methods designed to solve the bin packing problem (BPP) or the simple trip packing problem (STTP) can not be used to solve the GTPP.

Finally, it is worth noting that in practice we have about one hour to solve the petrol stations replenishment problem (PSRP). This should be done at the beginning of each day as petrol stations can issue orders at any time and ordered products should be delivered within the following 24 hours. The solution procedure proposed in [1] is an iterative procedure where each iteration consists in designing a set of trips and then solving the corresponding GTPP. Thus we need to design very fast trip packing methods.

\section{LITERATURE REVIEW}

As mentioned above, to the best of our knowledge, there is no publication that deals with the GTPP. Moreover, there are few publications that deal with the simple trip packing problem (STPP). Most of these publications use an adaptation of the BFD (best fit decreasing) heuristic to solve the packing problem. Most of these publications consider the case of homogeneous fleets.

Fleischmann [4] was the first to address the STPP as a sub-problem of the MTVRP. He proposed a modified version of the savings algorithm (Clarke and Wright [12]) to design a set of feasible trips and used a bin packing heuristic to assign trips to trucks. Taillard et al. [5] proposed a three-phase approach to solve the MTVRP. First they used the Tabu search heuristic of Rochat and Taillard [13] to generate a set of trips. Then they constructed a set of solutions as if each 
vehicle is used for only one trip. Finally they used a bin packing heuristic to allocate trips to vehicles. Golden et al. [6] solved the MTVRP with the objective of minimizing the longest trip. They used a Tabu search procedure to produce several solutions for the VRP and then used an adaptation of the BFD and an interchange procedure to assign trips to trucks.

Zhao et al. [7] proposed a Tabu search heuristic with an embedded bin packing procedure. Thus, within the Tabu search, each visited neighbour solution is evaluated only after assigning trips to vehicles. Petch and Salhi [8] developed methods to generate several solutions where each vehicle is used for only one trip and, for each solution, used a modified version of the BFD to assign trips to vehicles. The best obtained MTVRP solution is then retained. In all these contributions, the fleet is composed of an unlimited number of identical vehicles (unlimited homogeneous fleet).

Olivera and Viera [9] also decompose the MTVRP and solve the trip packing sub-problem as bin packing problem. Although they consider a limited number of identical vehicles (limited homogeneous fleet), their objective is to minimize the number of vehicles to use. They indicate that they failed to solve some of their test instances.

Finally, as mentioned above, only Prins [11] considered the MTVRP with heterogeneous unlimited fleet. He assumed that all trucks have the same maximum working hours and decomposed the problem into two sub-problems: trip construction and trip packing. He developed some heuristics to construct individual trips and suggested using an adaptation of the FFD (first fit decreasing) algorithm to pack trips into a minimum number of trucks. Trip revenue and cost are not taken into consideration.

Unfortunately, none of the above mentioned trip packing methods can be used to solve the GTPP as they are not designed to maximize the overall net revenue and often unable to pack trips for a heterogeneous limited fleet. Furthermore, these methods are not designed to handle the possibility of working overtime hours in addition to regular hours. 


\section{PROBLEM FORMULATION}

This paper considers the GTPP arose in solving the petrol station replenishment problem (see Taqa Allah et al. [14], Malépart et al. [15], Cornillier et al. [16] and Cornillier et al. [17]). This real-life problem is considered under the following assumptions:

1. There are a limited number of non identical tank-trucks. Trucks are owned by the transportation company and, consequently, the fixed costs of trucks (depreciation and regular maintenance cost) are paid whether they are used or not;

2. In addition to regular working hours, each driver can work a limited number of overtime hours;

3. When drivers work overtime, they are paid a number of hours equal to the smallest integer larger than or equal to real overtime worked;

4. For each truck, some trips are feasible and others are not depending on truck characteristics and capacity;

5. Trip revenue and variable cost depends on the truck to be used for the trip but trip duration is the same whichever the truck used.

The following notation will be used to formulate the generalized trip packing problem (GTPP) considered in this paper:

\section{Parameters:}

$T \quad$ set of trips to be packed; $|T|=n$

$J \quad$ set of available trucks; $|J|=m$

i trip index; $i \in T$

$j \quad$ truck index; $j \in J$

$L \quad$ maximum number of regular work hours

$M \quad$ maximum number of overtime hours

C marginal cost per overtime hour

$d_{i} \quad$ duration of trip $i$ (in hours)

$J_{i} \quad$ set of trucks that can perform trip $i,\left|J_{i}\right|=m_{i}$

$T_{j} \quad$ set of trips that can be carried out by truck $j$

$V_{i j} \quad$ net revenue (revenue minus variable operating cost) of trip $i$ if assigned to truck $j$ 


\section{Decision variables:}

$x_{i j} \quad$ binary equals 1 if trip $i$ is assigned to truck $j$

$O_{j} \quad$ overtime hours for truck $j$

Using this notation, the generalized trip packing problem can be formulated as follows.

Find: $\quad O_{j}$ integer $\geq 0$ and $x_{i j} \in\{0,1\}, \forall i \in T$ and $\forall j \in J$ which:

Maximize: $\quad Z=\sum_{i \in T} \sum_{j \in J_{i}} V_{i j} x_{i j}-C \sum_{j \in J} O_{j}$

Subject to:

$$
\begin{array}{ll}
\sum_{j \in J_{i}} x_{i j}=1 & ; \forall i \in T \\
\sum_{i \in T_{j}} d_{i} x_{i j}-O_{j} \leq L & ; \forall j \in J \\
O_{j} \leq M & ; \forall j \in J
\end{array}
$$

In this formulation, the objective is to maximize the overall net revenue of operations (sum over all trips of net revenue minus the marginal cost of overtime hours). Notice that $O_{j}$ should take an integer value (see assumption 3). The first set of constraints assigns each trip to one and only one truck. The second set allows determining the overtime hours for each truck and the third set prevent overtime hours from exceeding the given upper limit.

Proposition The generalized trip packing problem (GTPP) is NP-hard.

Proof: To prove that GTTP is NP-hard we are going to use the restriction technique (see Garey and Johnson [18] page 63). So we are going to show that a special case of GTTP is NPhard.

Let us consider the special case where $M=0$ (no overtime hours and all working hours are regular hours). This implies that we no longer need neither the decision variable $O_{j}$ nor the third constraint of the above given formulation. The model for this special case is:

Find: $\quad x_{i j} \in\{0,1\}, \forall i \in T$ and $\forall j \in J$ which:

Maximize: $\quad \sum_{i \in T} \sum_{j \in J_{i}} V_{i j} x_{i j}$

$\begin{array}{ll}\text { Subject to: } & \sum_{j \in J_{i}} x_{i j}=1 \quad ; \forall i \in T \\ & \sum_{i \in T_{j}} d_{i} x_{i j} \leq L\end{array}$ 
Thus this special case is a maximum sum generalized assignment problem. It can be easily transformed into a minimum sum problem by replacing $V_{i j}$ by $V-V_{i j}$ where $V \geq \max _{i, j} V_{i j}$. Now, Sahni and Gonzalez [19] showed that the minimum sum generalized assignment problem is NPhard. This completes the proof that GTTP is NP-hard.

\section{Numerical illustration}

Let us consider an example where we need to assign 10 trips $(n=10)$ to 4 trucks $(m=4)$ over a period including 12 regular working hours $(L=12)$ and at most 3 overtime hours $(M=3)$. The marginal cost of overtime hours is $1(C=1)$. Trip durations and net revenues are given in Table 1 where NF indicates unfeasible assignments.

Table 1: Duration and revenues for the numerical example

\begin{tabular}{|l|l|l|l|l|l|l|l|l|l|l|}
\hline$i$ & 1 & 2 & 3 & 4 & 5 & 6 & 7 & 8 & 9 & 10 \\
\hline$d_{i}$ & 3.5 & 5.5 & 3 & 4.5 & 7 & 7.5 & 2 & 9 & 4.5 & 3.5 \\
\hline \hline$V_{i 1}$ & 10 & 8 & NF & 10 & 9 & NF & 9 & NF & 8 & 9 \\
\hline$V_{i 2}$ & 9 & 10 & NF & 9 & 10 & 9 & NF & 8 & 10 & NF \\
\hline$V_{i 3}$ & NF & NF & 9 & 8 & 10 & 8 & 10 & 9 & NF & 8 \\
\hline$V_{i 4}$ & 9 & 10 & 8 & 10 & NF & 10 & NF & 9 & 9 & NF \\
\hline
\end{tabular}

For this numerical example, the optimal solution as obtained by the commercial MIP code CPLEX (version 11.0) is:

- $\quad$ Trips 1, 4 and 10 assigned to truck 1 (total duration 11.5 hours);

- $\quad$ Trips 5 and 9 assigned to truck 2 (total duration 11.5 hours);

- $\quad$ Trips 3, 7 and 8 assigned to truck 3 (total duration 14 hours); and

- $\quad$ Trips 2 and 6 assigned to truck 4 (total duration 13 hours).

This solution gives a sum of net revenues of 97 and 3 overtime hours. Thus $Z^{*}=94$.

\section{PROPOSED HEURISTICS}

In this paper we propose several heuristic methods to solve the GTPP. First, we present six construction heuristics that can produce solutions in extremely short computation times. Second we introduce four improvement heuristics that can be used to improve solutions produced by the 
construction heuristics. Third, we develop a multi-start local improvement heuristic that combines construction and improvement heuristics. Finally, we propose an adaptation of the simulated annealing algorithm with multiple reheating cycles introduced by Boctor [20]. It worth noting that, although we used these heuristics to maximize the overall net revenue, it is straightforward to modify them in order to optimize any of the other alternative objectives discussed in section 1 .

\subsection{CONSTRUCTION HEURISTICS}

The proposed construction heuristics are greedy heuristics. They order trips based on one of their characteristics and assign them to trucks one by one according to this order. If we fail to assign one of the trips, we modify the order by moving this trip to the top of the list and try again to assign trips to trucks according to the new order. This is done at most $Q_{\max }$ times where $Q_{\max }$ is a parameter to be chosen by the user. If, in spite of these attempts, no feasible solution is obtained, we conclude that the heuristic is unable to solve the considered problem instance.

\section{Heuristic C1}

1. Number trips according to one of their characteristics (e.g., in descending order of their duration $d_{i}$ or in ascending order of $m_{i}$, the number of trucks able to perform them, or randomly). Set $Q=0$.

2. Increment $Q$. If $Q>Q_{\max }$ then the heuristic fails to find a feasible solution. Otherwise, set all trips free (unassigned) and $u_{j}=0, \forall j \in J$ ( $u_{j}$ is the sum of the duration of trips assigned to truck j). Go to step 3.

3. For $i=1$ to $n$, do

3.1 Assign trip $i$ to the truck that can perform it within its regular hours (i.e., such that $u_{j}+d_{i} \leq L$,) while adding the largest trip net revenue $V_{i j}$. Let $k$ be the selected truck, update $u_{k}$ (i.e., set $\left.u_{k}=u_{k}+d_{i \cdot}\right)$

3.2 If there is no such truck, assign trip $i$ to the truck $k$ that leads to the largest increase of the objective function (overall net revenue); i.e.:

$$
k=\arg \max _{j}\left\{V_{i j}-C\left(\left\lceil u_{j}+d_{i}-L\right\rceil-O_{j}\right) \mid u_{j}+d_{i} \leq L+M\right\},
$$

where $O_{j}$ is the overtime hours of truck $j$ before assigning trip $i$ to it. In case of tie choose the truck having the smallest number. Update $u_{k}\left(u_{k}=u_{k+} d_{i}\right)$. 
3.3 If trip $i$ is still not assigned, find all other already-assigned trips $\ell$ that can be reassigned to another truck, say $k$ (i.e., $u_{k}+d_{\ell} \leq L+M$ ), leaving enough time to allow adding trip $i$ to the original truck of $\ell$, say truck $j$ (i.e., such that $u_{j}+d_{i}-d_{\ell} \leq L+M$ ). Let $\ell^{*}$ be the best trip to be reassigned (i.e., the one allowing to achieve the highest overall net revenue), $j^{*}$ be its original truck and $k^{*}$ be the truck to which it can be added. Move trip $\ell^{*}$ to $k^{*}$ and add trip $i$ to $j^{*}$. Update $u_{k^{*}}$ and $u_{j *}$.

3.4 If trip $i$ is still free, move it to the top of the trip list and go back to step 2 .

Step 3.3 requires examining at most $n$ possible reassignments and is embedded in step 3 which is repeated $n$ times. In addition, the main loop of the heuristic (steps 2 and 3 ) is repeated at most $Q_{\max }$ times. Thus the complexity of this construction heuristic is $O\left(Q_{\max } n^{2}\right)$.

\section{Heuristic C2}

Heuristic $C 2$ is similar to $C 1$ except that we modify step 3.1 as follows:

3.1 If trip $i$ is free, assign it to the truck that can do it within its regular hours (i.e., such that $u_{j}+d_{i} \leq L$, where $u_{j}$ is the sum of the duration of trips assigned to truck $j$ ) while adding the largest value to the objective function. Update $u_{j}$ and if there is a trip such that its duration equals $L-u_{j}$, then assign it to $j$. In case of tie assign the one adding the highest net revenue.

Obviously, the complexity of heuristic $C 2$ is the same as that of $C 1$; i.e.; $O\left(Q_{\max } n^{2}\right)$.

\section{Variants of the proposed construction heuristics}

Several versions of the proposed construction heuristics will be tested. We call $C 1 d$, the version of $C 1$ where trips are numbered in descending order of their duration, $C 1 \mathrm{~m}$, the version where trips are numbered in ascending order of the number of trucks able to perform them, and $C 1 r$, the version where trips are numbered randomly. Heuristics $C 2 d, C 2 m$ and $C 2 r$ can be defined similarly.

\subsection{IMPROVEMENT HEURISTICS}

Four local improvement heuristics were developed and are presented hereafter. 


\section{Heuristic I1}

The idea of this improvement heuristic is to move trips to different trucks as long as this can improve the value of overall net revenue. Figure 1 gives the steps of the heuristic.

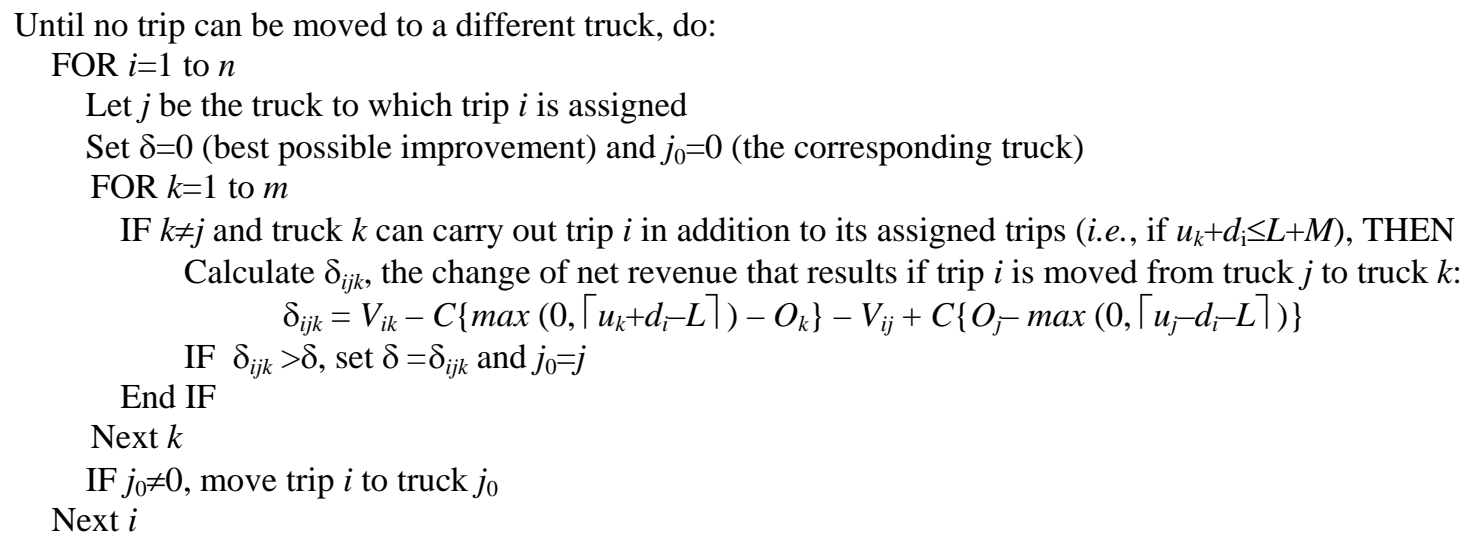

Figure 1: Pseudo code of the heuristic I1

Within each iteration of this improvement heuristic we examine the possibility of moving each of the $n$ trips to each of the $m-1$ alternative trucks. Thus the complexity of each iteration of this improvement heuristic is $O(m n)$. Obviously, we can not predict the number of iterations needed to reach a local optimum. This implies that we cannot determine the complexity of the heuristic as a whole.

\section{Heuristic I2}

Within this heuristic we consider every pair of trips, say $i$ and $l$, assigned to two different trucks, say $j$ and $k$ respectively. We reassign trip $i$ to truck $k$ and trip $l$ to truck $j$ as long as this allows improving the value of the overall net revenue. It works as shown by the following pseudo code given by Figure 2.

In the worst case (where there are only 2 trucks with $n / 2$ trips assigned to each of them), each iteration of this heuristic evaluates the impact of $\frac{n^{2}}{4}$ pair-exchanges; thus the complexity of one iteration is $O\left(n^{2}\right)$. Again, we can not predict the number of iterations needed to reach a local optimum. 
Until no pair of trips exchange their trucks do:

FOR $i=1$ to $n-1$

Let $j$ be the truck to which trip $i$ is assigned

Set $\delta=0$ (best possible improvement), $l_{0}=0$ (the corresponding trip) and $k_{0}=0$ (the corresponding truck)

FOR $l=i+1$ to $n$

Let $k$ be the truck to which trip $l$ is assigned

IF $k \neq j$ and trips $i$ and $l$ can be permuted (i.e., if $u_{k}+d_{i}-d_{l} \leq L+M$ and $u_{j}+d_{l}-d_{i} \leq L+M$ ), THEN

Calculate $\delta_{i j l k}$, the change in net revenue that results from this exchange:

$\delta_{i j l k}=V_{i k}-V_{i j}+C\left\{O_{k}-\max \left(0,\left\lceil u_{k}+d_{i}-d_{l}-L\right\rceil\right)\right\}+V_{l j}-V_{l k}+C\left\{O_{j}-\max \left(0,\left\lceil u_{j}+d_{l}-d_{i}-L\right\rceil\right)\right\}$

IF $\delta_{i j l k}>\delta$, set $\delta_{=} \delta_{i j l k}, l_{0}=l$ and $k_{0}=k$

\section{End IF}

Next $l$

IF $l_{0} \neq 0$, move trip $i$ to truck $k_{0}$ and trip $l_{0}$ to truck $j$

Next $i$

Figure 2: Steps of the heuristic $I 2$

\section{Heuristic I3:}

Within this heuristic we consider every triplet of trips, say $i, l$ and $t$, such that $i$ and $l$ are assigned to the same truck, say $j$, while trip $t$ is assigned to different truck, say $k$. We reassign trips $i$ and $l$ to truck $k$ and reassign $t$ to truck $j$, as long as this allows improving the value of the overall net revenue. The steps of this heuristic are given in Figure 3.

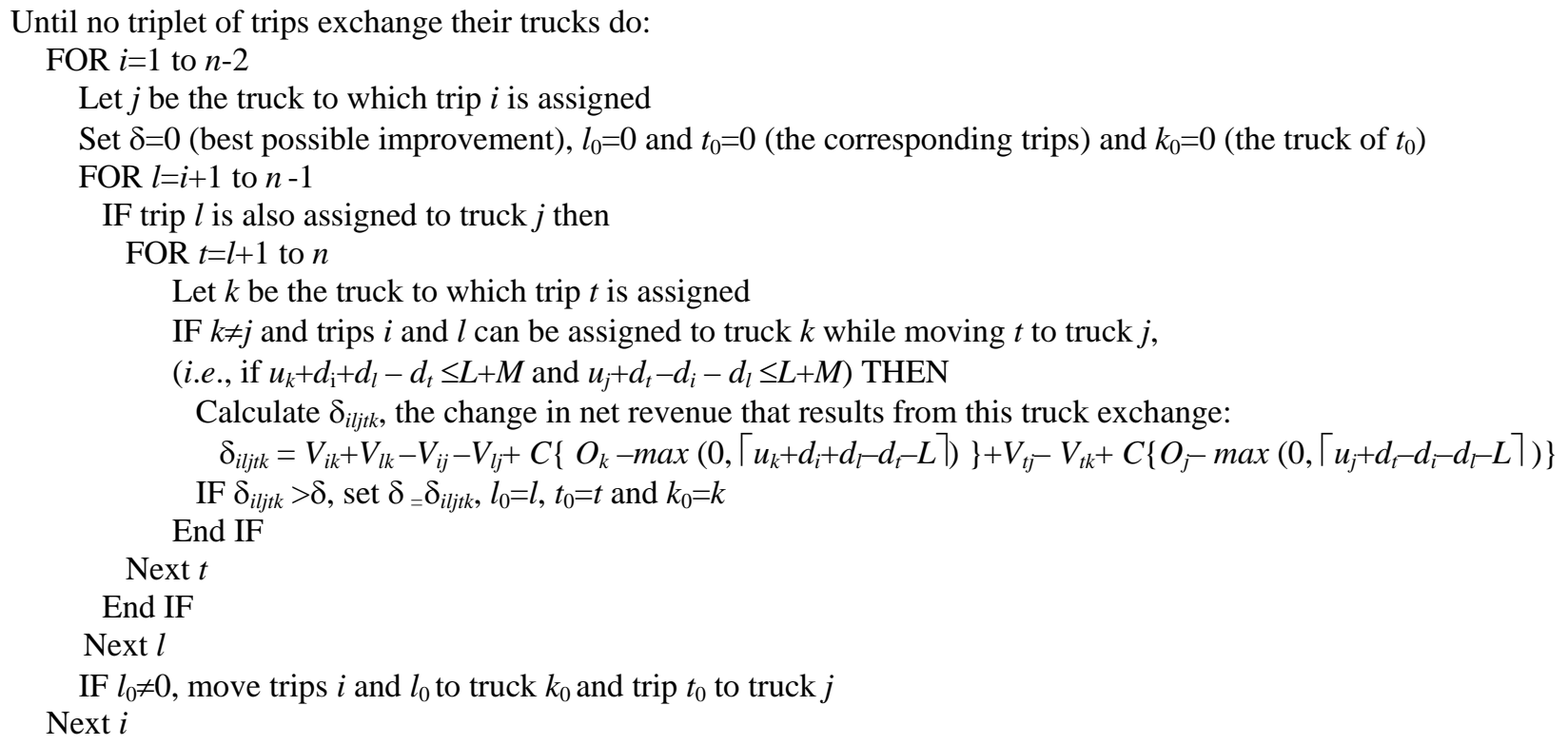

Figure 3: Pseudo code of the improvement heuristic I3 
In the worst case (where there are only 2 trucks with $n / 2$ trips assigned to each of them), each iteration of this heuristic evaluates the impact of $\frac{n^{2}}{4}\left(\frac{n}{2}-1\right)$ triplet-exchanges; thus the complexity of each iteration is $O\left(n^{3}\right)$. Again we cannot predict the number of iterations needed to reach a local optimum.

\section{Heuristic I4:}

Within this heuristic we consider every triplet of trips, say $i, l$ and $t$, assigned to three different trucks, say $j, k$ and $v$ respectively, and reassign $i$ to $k, l$ to $v$ and $t$ to $j$, as long as this improves the value of the overall net revenue. The heuristic works as shown by the pseudo code given by

\section{Figure 4.}

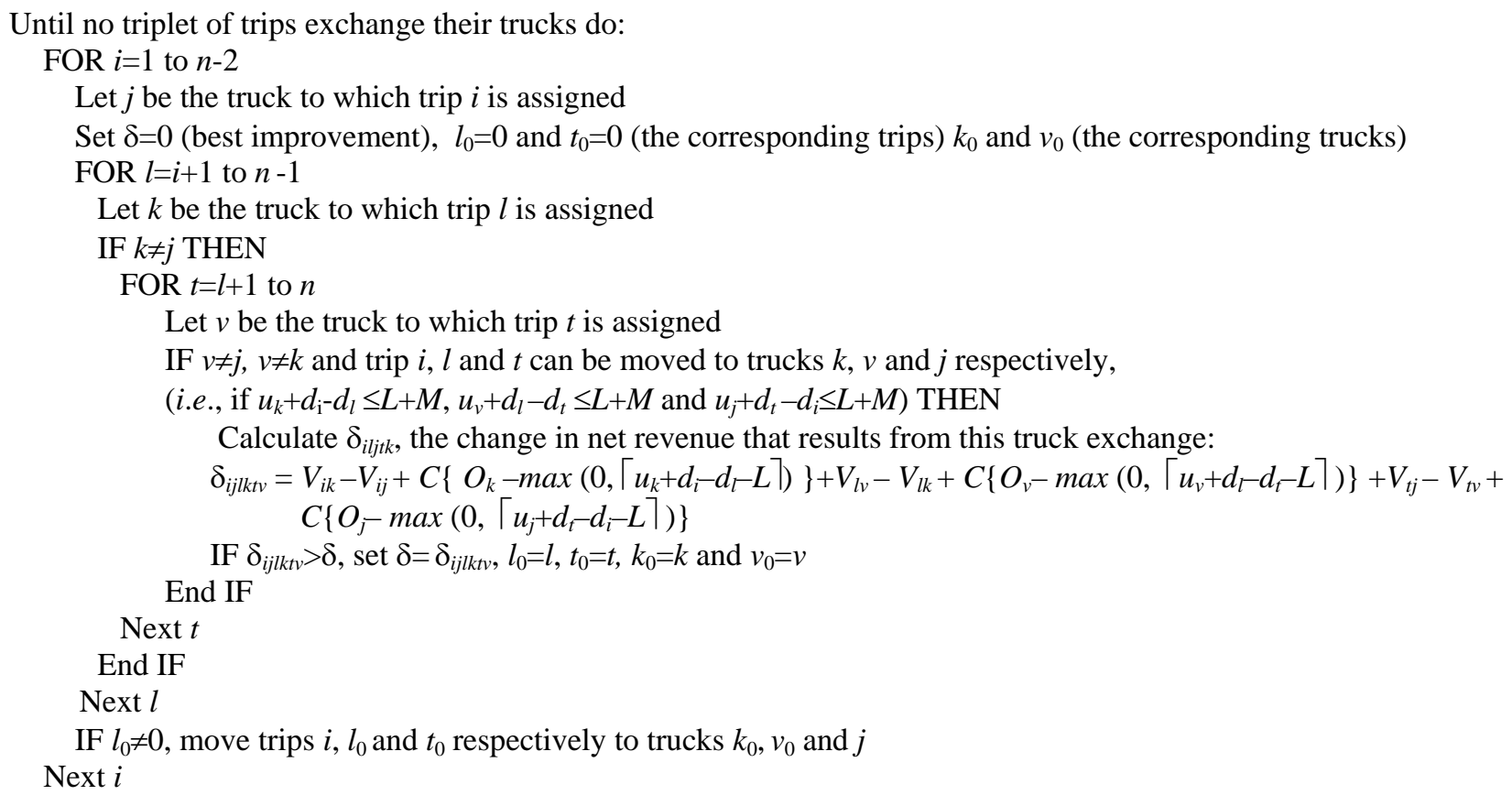

Figure 4: Pseudo code of the improvement heuristic I4

In the worst case (where there are only 3 trucks with $n / 3$ trips assigned to each of them), each iteration of this heuristic evaluates the impact of $\frac{n^{3}}{27}$ triplet-exchanges; thus the complexity of each iteration is $O\left(n^{3}\right)$. 


\section{Numerical illustration}

In the following we apply some of the proposed heuristics to the numerical example presented in section 3.

\section{Heuristic C1d}

In step 1 we arrange trips in descending order of their duration. In step 2 we set all trips free and all trucks unused. The needed iterations of step 3 are summarized in Table 2. Applying the proposed improvement heuristics to the obtained solution leads to the following results. Heuristic $\mathbf{I} 1$ does not lead to any improvement. $\boldsymbol{I} 2$ brings us to move trip 1 to truck 1 and trip 2 to truck 4 leading to overall net revenue of 94 . I3 and $\mathbf{I 4}$ produce no further improvement.

\section{Heuristic C2d}

The needed iterations of step 3 are summarized in Table 3. The second row of the table shows that trip 3 was selected (in application of step 3.1) as its duration equals the remaining time of truck $3\left(d_{3}=L-u_{3}\right)$. Applying $\mathbf{I 1}$ to the obtained solution does not lead to any improvement. $\mathbf{I} 2$ brings us to move trip 2 to truck 4 and trip 4 to truck 1 leading to overall net revenue of 94 . I3 and $\mathbf{I 4}$ bring no further improvement.

Table 2: Step 3 of heuristic $C 1 d$

\begin{tabular}{|c|c|c|c|c|c|c|c|}
\hline \multirow[t]{2}{*}{ Trip } & \multirow[t]{2}{*}{ Duration } & \multirow{2}{*}{$\begin{array}{c}\text { Selected } \\
\text { Truck }\end{array}$} & \multirow{2}{*}{$\begin{array}{c}\text { Truck net } \\
\text { revenue minus } \\
\text { overtime cost }\end{array}$} & \multicolumn{4}{|c|}{$\begin{array}{l}\text { Remaining regular (used } \\
\text { overt time) hours of truck }\end{array}$} \\
\hline & & & & 1 & 2 & 3 & 4 \\
\hline 8 & 9 & 3 & 9 & 12 & 12 & 3 & 12 \\
\hline 6 & 7.5 & 4 & 10 & 12 & 12 & 3 & 4.5 \\
\hline 5 & 7 & 2 & 10 & 12 & 5 & 3 & 4.5 \\
\hline 2 & 5.5 & 1 & 8 & 6.5 & 5 & 3 & 4.5 \\
\hline 4 & 4.5 & 1 & 10 & 2 & 5 & 3 & 4.5 \\
\hline 9 & 4.5 & 2 & 10 & 2 & 0.5 & 3 & 4.5 \\
\hline 1 & 3.5 & 4 & 9 & 2 & 0.5 & 3 & 1 \\
\hline 10 & 3.5 & 1 & $9-2$ & $(1.5)$ & 0.5 & 3 & 1 \\
\hline 3 & 3 & 3 & 9 & $(1.5)$ & 0.5 & 0 & 1 \\
\hline 7 & 2 & 3 & $10-2$ & $(1.5)$ & 0.5 & $(2)$ & 1 \\
\hline \multicolumn{3}{|c|}{ Overall net revenue } & 90 & & & & \\
\hline
\end{tabular}


Table 3: Step 3 of heuristic $C 2 d$

\begin{tabular}{|c|c|c|c|c|c|c|c|}
\hline \multirow[t]{2}{*}{ Trip } & \multirow[t]{2}{*}{ Duration } & \multirow{2}{*}{$\begin{array}{c}\text { Selected } \\
\text { Truck }\end{array}$} & \multirow{2}{*}{$\begin{array}{l}\text { Truck revenue } \\
\text { minus } \\
\text { overtime cost }\end{array}$} & \multicolumn{4}{|c|}{$\begin{array}{l}\text { Remaining regular (used } \\
\text { overt time) hours of truck }\end{array}$} \\
\hline & & & & 1 & 2 & 3 & 4 \\
\hline 8 & 9 & 3 & 9 & 12 & 12 & 3 & 12 \\
\hline 3 & 3 & 3 & 9 & 12 & 12 & 0 & 12 \\
\hline 6 & 7.5 & 4 & 10 & 12 & 12 & 0 & 4.5 \\
\hline 4 & 4.5 & 4 & 10 & 12 & 12 & 0 & 0 \\
\hline 5 & 7 & 2 & 10 & 12 & 5 & 0 & 0 \\
\hline 2 & 5.5 & 1 & 8 & 6.5 & 5 & 0 & 0 \\
\hline 9 & 4.5 & 2 & 10 & 6.5 & 0.5 & 0 & 0 \\
\hline 1 & 3.5 & 1 & 10 & 3 & 0.5 & 0 & 0 \\
\hline 10 & 3.5 & 1 & $9-1$ & $(0.5)$ & 0.5 & 0 & 0 \\
\hline 7 & 2 & 3 & $10-2$ & $(0.5)$ & 0.5 & (2) & 0 \\
\hline \multicolumn{3}{|c|}{ Overall net revenue } & 92 & & & & \\
\hline
\end{tabular}

\subsection{MULTI-START LOCAL IMPROVEMENT HEURISTIC (MSLIH)}

The general framework of the proposed Multi-Start Local Improvement Heuristic (MSLIH) is:

Repeat the following steps $P$ times and retain the best solution obtained:

0 - Set $p=0$

1- Construct a new initial solution. Set $p=p+1$

2- Apply the improvement heuristics $I 1$.

3- Apply I2. If an improved solution is found go back to step 2.

4- Apply I3. If an improved solution is found go back to step 2.

5- Apply I4. If an improved solution is found go back to step 2.

6- IF $p<P$ Go to step 1.

To find a new initial solution we can apply a different construction heuristic each time. Also if we apply $C 1 r$ or $C 2 r$ several times with different random seeds we may obtain different solutions. The value of the parameter $P$ is chosen by the user.

\subsection{ADAPTATION OF THE SIMULATED ANNEALING ALGORITHM (SA)}

The general framework of the proposed adaptation of the simulated annealing (SA) algorithm is given in Figure 5. Within this adaptation we execute $H$ heating cycles and within each cycle we 
start with an initial temperature $T_{\max }$ and end with a final temperature $T_{\min }$. The temperature is reduced (using a reduction coefficient $\alpha$ ) once we reach $R_{\max }$ iterations without improving the best feasible solution found so far. It has been shown (Boctor [19]) that performing several heating cycles improves the final results. It was also shown in this same paper that a well designed adaptation of the SA algorithm can outperform other metaheuristics. That is why we decided to use SA to solve our problem.

At each iteration of our SA algorithm, we examine a neighbour of the current solution. Three neighbourhood structures are used and we randomly select one of them. Then we randomly select one neighbour in the randomly selected neighbourhood. These neighbourhood structures are:

(1) Move a randomly selected trip to a randomly selected truck;

(2) Permute the trucks of two randomly selected trips, and;

(3) Randomly select three trips (say $i, j$ and $k$ ) assigned to three different trucks and circularly permute the trucks of the selected trips (i.e.; move $i$ to the truck of $j, j$ to the truck of $k$ and $k$ the truck of $i$ ).

- Use a construction heuristic to construct an initial feasible solution

- Store the obtained solution as the current solution and as the best solution found so far

- Initialize the heating cycle counter $h:=0$

- Repeat until $h=H$

$-h=h+1$

- Initialize the cooling temperature $\tau=T_{\max }$

- Repeat until $\tau<T_{\min }$

- Initialize the repetition counter $r=0$

- Repeat until $r=R_{\max }$

- Randomly select a neighbourhood definition

- Randomly select a neighbour of the current solution from the selected neighbourhood

- Let $\delta$ be the difference between the value associated to the neighbour solution and that of the current solution

- If $\delta>0$ or a randomly drawn value is less than $\mathrm{e}^{-\delta / \tau}$ then

- Store the neighbour solution as the new current solution

- If the neighbour solution is feasible and better than the best found so far, store it as the new - End If best solution and set $r=0$

- End Repeat

- Set $\tau=\alpha \tau$

- End Repeat

- End Repeat

Figure 5: General Framework of the proposed adaptation of the simulated annealing algorithm 
A selected neighbour solution could be either feasible or unfeasible. Unfeasible solutions are penalized as follows. A penalty $p_{1}$ is added for each trip assigned to a truck that cannot carry it out and another penalty $p_{2}$ is added for every working hour exceeding allowable hours. Penalizing unfeasible solutions instead of always rejecting them allows investigating larger number of different neighbours and reduces the chance that the search procedure is trapped in a local optimum.

\section{A DYNAMIC PROGRAMMING FORMULATION}

The Generalized Trip Packing Problem (GTPP) can be seen as a clustering or partitioning problem. There are two types of partitioning problems: restricted and unrestricted partitioning. Unrestricted partitioning implies that an element can be assigned to any cluster without restrictions. In the case of the GTPP we have to partition the $n$ trips into at most $m$ subsets in a way that maximizes overall net revenue. It is a restricted partitioning problem as some trips can not be assigned to a given truck and the sum of the duration of trips assigned to any truck should be less than or equal to the allowable working time.

There are very few papers that present a dynamic programming solution approaches to solve unrestricted partitioning problems and, to the best of our knowledge, there is no publication that proposes such approach for any restricted partitioning problem. Jensen [21] was the first to suggest using dynamic programming to deal with unrestricted partitioning problems. Hubert, Arabie and Meulman [22] were the first to provide a complete FORTRAN program to solve them. Van Os and Meulman [23] proposed to improve this method by removing redundant solutions. However, as they noted, removing redundancy slow down the process and consequently a balance should be sought between fast implementations with (some) redundancy and slower implementations that is completely non-redundant.

The GTPP can be formulated as a dynamic program as follows. Let us define $E_{j}$ as a subset of trips that can be carried out by truck $j$ within the maximal allowable (regular and overtime) work hours, $V_{j}\left(E_{j}\right)$ as the total net revenue that truck $j$ collect from carrying out the trips of $E_{j}, O_{j}\left(E_{j}\right)$ as the corresponding overtime cost and $W_{j}\left(E_{j}\right)=V_{j}\left(E_{j}\right)-O_{j}\left(E_{j}\right)$ as the truck net revenue. The problem is to find a collection of $m$ mutually exclusive and exhaustive subsets of $I$, say $E=\left\{E_{1}, \ldots, E_{m}\right\}$, 
which maximizes $W_{m}(I)$, the sum over all the $m$ trucks of $W_{j}\left(E_{j}\right)$. Let $E^{j}$ be all trip subsets that can be carried out by truck $j, I_{j}$ all trip subsets that can be feasibly assigned to the first $j$ trucks, and $W_{j}^{*}\left(I^{\prime}\right)$ denote the optimal value corresponding to the optimal assignment of $I^{\prime} \subseteq I_{j}$ to the $j$ first trucks. Assuming that there is a feasible assignment of $I^{\prime}$ to the $j$ first trucks, then, dynamic programming provides an optimal solution by using the recursion:

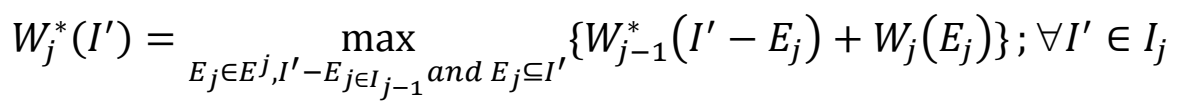

The overall optimal solution is then given by $W_{m}^{*}(T)$. Recall that $T$ is the whole set of trips.

To solve this dynamic program we need to calculate $W_{j}\left(E_{j}\right)$ for every truck $j$ and for every trip subset $E_{j}$ that can be carried out by $j$ within allowable working hours. The complexity of this step is $O\left(m 2^{n}-1\right)$. We also need to enumerate all the subsets $I_{j} ; j=1, . ., m$. This requires a huge storage capacity and makes it impossible to solve real-life problems.

Alternatively, we may transform the GTPP into an unrestricted problem by assigning a large negative revenue to trip subsets that are not feasible for the considered truck. In this case we can use the FORTRAN Code provided by Van Os and Meulman [22]. But still we need to calculate $W_{j}\left(E_{j}\right)$ for every truck $j$ and for every trip subset $E_{j}$ that can be carried out within allowable working hours. However, as noted by Van Os and Meulman, the number of recursive evaluations is of order $O\left(3^{n}\right)$ and the storage capacity needed is of order $O\left(m 2^{n}\right)$. They stated that as a result of these requirements, the maximum problem size to be handled by modern desktop computers is in the range of 25 to 29. They also concluded that it is not expected that this limit will be extended in the near future given the order $O\left(3^{n}\right)$ of the algorithm. They also indicated that on a PC with a Pentium IV $3.1 \mathrm{GHz}$ processor it took 14 hours and 1.4 GB memory to solve an unrestricted portioning problem with 26 elements and 7 clusters. In addition they indicated that the computation time is multiplied by a factor between 2.7 and 3.7 each time we add a new element the set to be partitioned. Thus if we increase the size of their problem to 50 elements, partitioning the set should require $3^{24}$ times 14 hours; which is about 451 million years. Unfortunately, this implies that we are not able to solve our 50 trips-15 trucks GTPP test instances by dynamic programming. 


\section{COMPUTATIONAL RESULTS}

There are no benchmark instances for the GTPP. Thus, one hundred instances of the problem were randomly-generated and used to assess the quality of the solutions produced by the proposed heuristics. These instances were generated in a way that reflects real-life situation. We have also solved a real life instance using data provided by a petrol products distributor in Eastern Quebec, Canada.

\subsection{RESULTS FOR THE RANDOMLY GENERATED TEST INSTANCES}

Each of the generated instances includes 50 trips and 5 truck types. The number of available trucks of each type is 4, 2, 4, 3 and 2 for a total of 15 trucks. This is the size of real-life instances that medium sized transportation companies usually encounter. It is also the size of the real-life instance we solved (see section 6.2). Durations and trip revenues are drawn from the empirical distribution driven from the data of the real-life instance. Regular working hours are 10 and there is a maximum of 5 overtime hours. Overtime hourly cost is 60 . These test instances can be obtained from the authors on a simple request.

The commercial MIP code CPLEX 11.0 was used and ran on a personal computer with a Xeon 3.6 GHz processor and 1.00 GB of RAM. CPLEX failed to solve any of the generated instances to optimality and produced an out of memory error for all instances. However CPLEX always produced an integer solution. In average, best obtained integer solutions are $0.208 \%$ worse than the best solution found heuristically. The best heuristic solution was better than the integer solution found by CPLEX for 88 instances and CPLEX produced a slightly better solution for 11 instances. The average run time of CPLEX (time to stoppage) was 1658 seconds with a standard deviation of 145 seconds. The average optimality gap was $0.7768 \%$.

We also tried to solve these instances using CPLEX with the strong branching variableselection option. This option requires less memory but often requires more computational times. Again CPLEX failed and reached an out of memory error after about 20000 seconds of computation time. 


\section{Results obtained by construction heuristics alone}

Table 4 presents the results obtained with each of the proposed construction heuristics alone (not followed by any improvement heuristic). Average computational time (clock time) for all these heuristics is less than 0.01 seconds. Table 4 shows that best results were obtained by $C 1 d$ followed by $C 2 d$. As CPLEX failed to reach the optimal solutions, the average deviation is calculated with respect to the best solution found with either CPLEX or any of the tested heuristics. The average deviation from the best obtained solution varies between $2.90 \%$ and $3.59 \%$. None of these construction heuristics produced the best solution for any of the test instances. $C 2 r$ produced the worst solution for 40 test instances.

Table 4: Results obtained by construction heuristics alone

\begin{tabular}{|l|c|c|c|c|c|c|}
\hline \multicolumn{1}{|c|}{ Heuristic } & $C 1 d$ & $C 2 d$ & $C 1 m$ & $C 2 m$ & $C 1 r$ & $C 2 r$ \\
\hline Average deviation from the best obtained solution & $2.91 \%$ & $2.92 \%$ & $3.31 \%$ & $3.27 \%$ & $3.58 \%$ & $3.60 \%$ \\
\hline Standard deviation & $0.45 \%$ & $0.47 \%$ & $0.48 \%$ & $0.56 \%$ & $0.53 \%$ & $0.54 \%$ \\
\hline Minimum deviation & $1.90 \%$ & $1.70 \%$ & $2.35 \%$ & $2.17 \%$ & $2.23 \%$ & $2.36 \%$ \\
\hline Maximum deviation & $4.04 \%$ & $4.04 \%$ & $4.56 \%$ & $5.15 \%$ & $5.05 \%$ & $5.25 \%$ \\
\hline Number of times it produced the best solution & 0 & 0 & 0 & 0 & 0 & 0 \\
\hline Number of times it produced the worst solution & 3 & 5 & 19 & 14 & 35 & 40 \\
\hline
\end{tabular}

\section{Results obtained by construction heuristics followed by improvement heuristics}

Table 5 presents the results obtained by each construction heuristic followed the improvement heuristics where each one was applied once. Again deviations are with respect to the best obtained solution among those given either by CPLEX or any of the tested heuristics. Table 5 shows that slightly better results can be obtained if the initial solution is produced by $C 1 d$ or $C 2 d$. However, using the means-comparison statistical test, we can conclude that there is no significant difference between the obtained average deviations. The average computing time (clock time) varies from 1.19 and 1.24 seconds. Although the average percentage deviation is less than $0.52 \%$, none of these heuristics produced the best found solution. 
Table 5: Results obtained by construction heuristics followed by each improvement heuristic once

\begin{tabular}{|l|c|c|c|c|c|c|}
\hline \multicolumn{1}{|c|}{ Initial solution by } & $C 1 d$ & $C 2 d$ & $C 1 m$ & $C 2 m$ & $C 1 r$ & $C 2 r$ \\
\hline Average deviation from the best obtained solution & $0.46 \%$ & $0.46 \%$ & $0.50 \%$ & $0.48 \%$ & $0.50 \%$ & $0.52 \%$ \\
\hline Standard deviation & $0.21 \%$ & $0.20 \%$ & $0.19 \%$ & $0.21 \%$ & $0.23 \%$ & $0.23 \%$ \\
\hline Minimum deviation & $0.04 \%$ & $0.01 \%$ & $0.15 \%$ & $0.08 \%$ & $0.06 \%$ & $0.01 \%$ \\
\hline Maximum deviation & $0.99 \%$ & $1.05 \%$ & $1.05 \%$ & $1.13 \%$ & $1.13 \%$ & $1.24 \%$ \\
\hline Number of times it produced the best solution & 0 & 0 & 0 & 0 & 0 & 0 \\
\hline Number of times it produced the worst solution & 0 & 0 & 0 & 0 & 0 & 0 \\
\hline Average computing (clock) time in seconds & 1.19 & 1.24 & 1.19 & 1.21 & 1.19 & 1.21 \\
\hline
\end{tabular}

\section{Multi-Start local improvement heuristic and best parameters}

Table 6 presents the results obtained for different values of $P$ while the initial solution was always constructed using $C 1 r$. As shown in the table very good results were obtained with $P=15$ or 20. With $P=20$, the multi-start local improvement heuristic gave a better solution than the best obtained by CPLEX for 65 of the 100 test instances while requiring in average less than 24 seconds. The table shows that average deviation from the best obtained solution improves as $P$ increases. However, computation time also increases as $P$ increases. Thus the value of $P$ should be chosen in function of the user's preferences.

Table 6: Results obtained using different values of $P$ (initial solution by $C 1 r$ )

\begin{tabular}{|l|c|c|c|c|c|c|}
\hline \multicolumn{1}{|c|}{ Number of restarts } & 2 & 3 & 5 & 9 & 15 & 20 \\
\hline Average deviation from the best solution found & $0.40 \%$ & $0.35 \%$ & $0.30 \%$ & $0.23 \%$ & $0.20 \%$ & $0.17 \%$ \\
\hline Standard deviation & $0.16 \%$ & $0.14 \%$ & $0.14 \%$ & $0.12 \%$ & $0.10 \%$ & $0.11 \%$ \\
\hline Minimum deviation & $0.01 \%$ & 0 & 0 & 0 & 0 & 0 \\
\hline Maximum deviation & $0.91 \%$ & $0.70 \%$ & $0.68 \%$ & $0.57 \%$ & $0.45 \%$ & $0.45 \%$ \\
\hline Number of times it produced the best solution & 0 & 2 & 1 & 3 & 2 & 4 \\
\hline Number of times it gave a better solution than CPLEX & 15 & 21 & 35 & 50 & 54 & 65 \\
\hline Average computation time (clock time) in seconds & 2.37 & 2.95 & 5.99 & 10.82 & 17.80 & 23.89 \\
\hline
\end{tabular}

\section{Simulated annealing and best heating and cooling schedules}

The proposed simulated annealing algorithm requires selecting the value of several parameters: $H$ the number of heating cycles, $T_{\max }$ the initial temperature, $T_{\min }$ the final temperature, $\alpha$ the temperature reduction coefficient and $R_{\max }$ the number of repetitions. We also need to fix the infeasibility penalties $p_{1}$ and $p_{2}$. A large number of parameter combinations were tested and Table 7 presents the results obtained by some of the best combinations of $H$ and $R_{\max }$ in the ascending order of their average computation time. For all the reported results we used: 
$T_{\max }=16, T_{\min }=1, \alpha=0.5, p_{1}=10000$ and $p_{2}=600$. Other values for these 5 parameters were also tested but it appeared that they have small effect on the quality of the obtained solutions.

From Table 7 we can see that average deviation decreases as computation time increases. It also shows that with $H=6$ and $R_{\max }=25000$, the heuristic produced an average deviation of $0.11 \%$ in 16.37 second of average time. Furthermore, comparing the results of Tables 6 and 7 we can conclude that, using the same computation time, our adaptation of the simulated annealing algorithm produces slightly better results than the multi-start local improvement heuristic (see Figure 6). For example, with approximately 11 seconds of computing time, the multi-start local improvement heuristic produced an average deviation of $0.22 \%$ while the simulated annealing adaptation produced an average deviation of $0.20 \%$.

Table 7: Results obtained the simulated annealing adaptation in function of its parameters

\begin{tabular}{|c|c|c|c|c|c|c|c|c|}
\hline$H$ & 6 & 6 & 10 & 6 & 10 & 6 & 10 & 10 \\
\hline$R_{\max }$ & 10000 & 15000 & 10000 & 20000 & 15000 & 25000 & 20000 & 25000 \\
\hline Average deviation from the best obtained solution & $0.26 \%$ & $0.19 \%$ & $0.21 \%$ & $0.16 \%$ & $0.17 \%$ & $0.11 \%$ & $0.13 \%$ & $0.11 \%$ \\
\hline Standard deviation & $0.13 \%$ & $0.13 \%$ & $0.11 \%$ & 0.13\% & $0.12 \%$ & $0.10 \%$ & $0.11 \%$ & $0.10 \%$ \\
\hline Minimum deviation & 0 & 0 & 0 & 0 & 0 & 0 & 0 & 0 \\
\hline Maximum deviation & $0.62 \%$ & $0.59 \%$ & $0.51 \%$ & $0.58 \%$ & $0.59 \%$ & $0.35 \%$ & $0.63 \%$ & $0.53 \%$ \\
\hline Number of times it produced the best solution & 2 & 4 & 2 & 12 & 8 & 18 & 16 & 18 \\
\hline Number of times it gave a better solution than CPLEX & 41 & 49 & 56 & 61 & 64 & 74 & 71 & 75 \\
\hline Average computation (clock) time in seconds & 6.51 & 9.79 & 10.86 & 13.10 & 16.33 & 16.37 & 21.81 & 27.08 \\
\hline
\end{tabular}

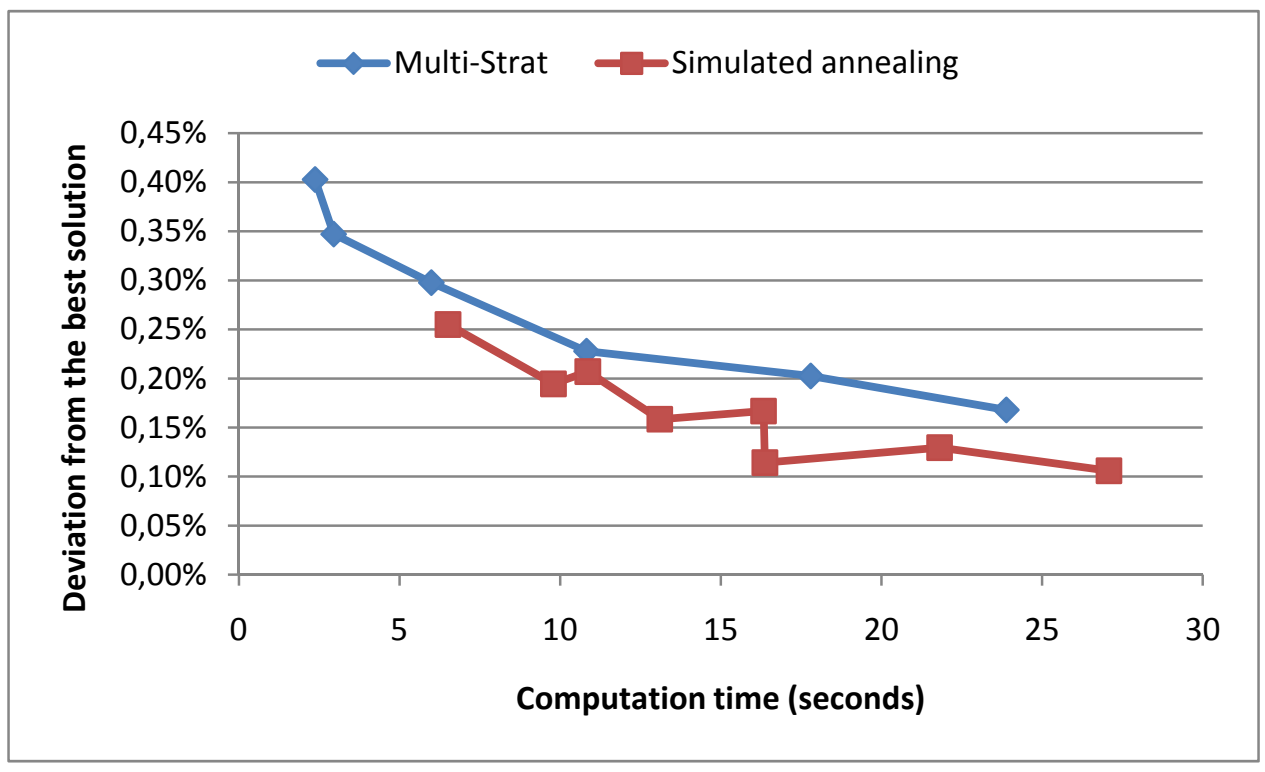

Figure 6: Average deviation from best obtained solution in function of computing time 


\subsection{RESULTS FOR THE REAL LIFE INSTANCE}

We used the data provided by a petrol products distributor in Eastern-Quebec for a single working day where 87 petrol stations are replenished using 51 routes and 14 trucks of 5 different configurations (see Table 8). The stations location is given on Figure 7 and the data for the 51 routes is given in the appendix. This real life instance was solved using 4 different scenarios:

Scenario A: 10 regular and 5 overtime hours with $C$ (marginal overtime cost / hour) $=30 \$$ Scenario B: 10 regular and 5 overtime hours with $C=60 \$$ Scenario C: 12 regular and 3 overtime hours with $C=30 \$$

Scenario D: 12 regular and 3 overtime hours with $C=60 \$$

Table 8: Truck types and numbers

\begin{tabular}{|c|c|c|c|c|c|c|c|c|c|}
\hline \multirow{2}{*}{$\begin{array}{c}\text { Truck } \\
\text { type }\end{array}$} & $\begin{array}{c}\text { Number } \\
\text { of } \\
\text { Tanks }\end{array}$ & $\begin{array}{c}\text { Total } \\
\text { capacity } \\
\text { (1000 litres) }\end{array}$ & 1 & 2 & 3 & 4 & 5 & 6 & $\begin{array}{c}\text { Number of } \\
\text { available } \\
\text { trucks }\end{array}$ \\
\hline 1 & 5 & 58 & 15 & 10 & 7.5 & 9.5 & 16 & - & 4 \\
\hline 2 & 6 & 60 & 17 & 6 & 10 & 10 & 7 & 10 & 2 \\
\hline 3 & 6 & 60 & 16 & 5 & 12 & 6 & 5 & 16 & 4 \\
\hline 4 & 6 & 54 & 15 & 7 & 5 & 5 & 8 & 14 & 2 \\
\hline 5 & 5 & 54 & 16 & 6 & 6 & 10 & 16 & - & 2 \\
\hline
\end{tabular}

We tried to solve these instances using CPLEX version 11.0. Unfortunately, it failed to find the optimal solution for any of the attempted scenarios and always produced an out of memory error. So we tried again while using its strong branching variable-selection option. Again, CPLEX failed to solve any of the scenarios and produced an out of memory error. However, in all these trials an integer solution was found before the program failure. The obtained solution was worse than the best solution obtained heuristically for 3 of the 4 tested scenarios. In the forth one (scenario C) a very close solution was found heuristically (overall net revenue of 12978 instead of 12981). Heuristic solutions are obtained in much shorter computation time (between 10.5 and 16.75 seconds). Solutions obtained by CPLEX 11 are given in table 9 and those obtained by the proposed heuristics are presented in Table 10. 


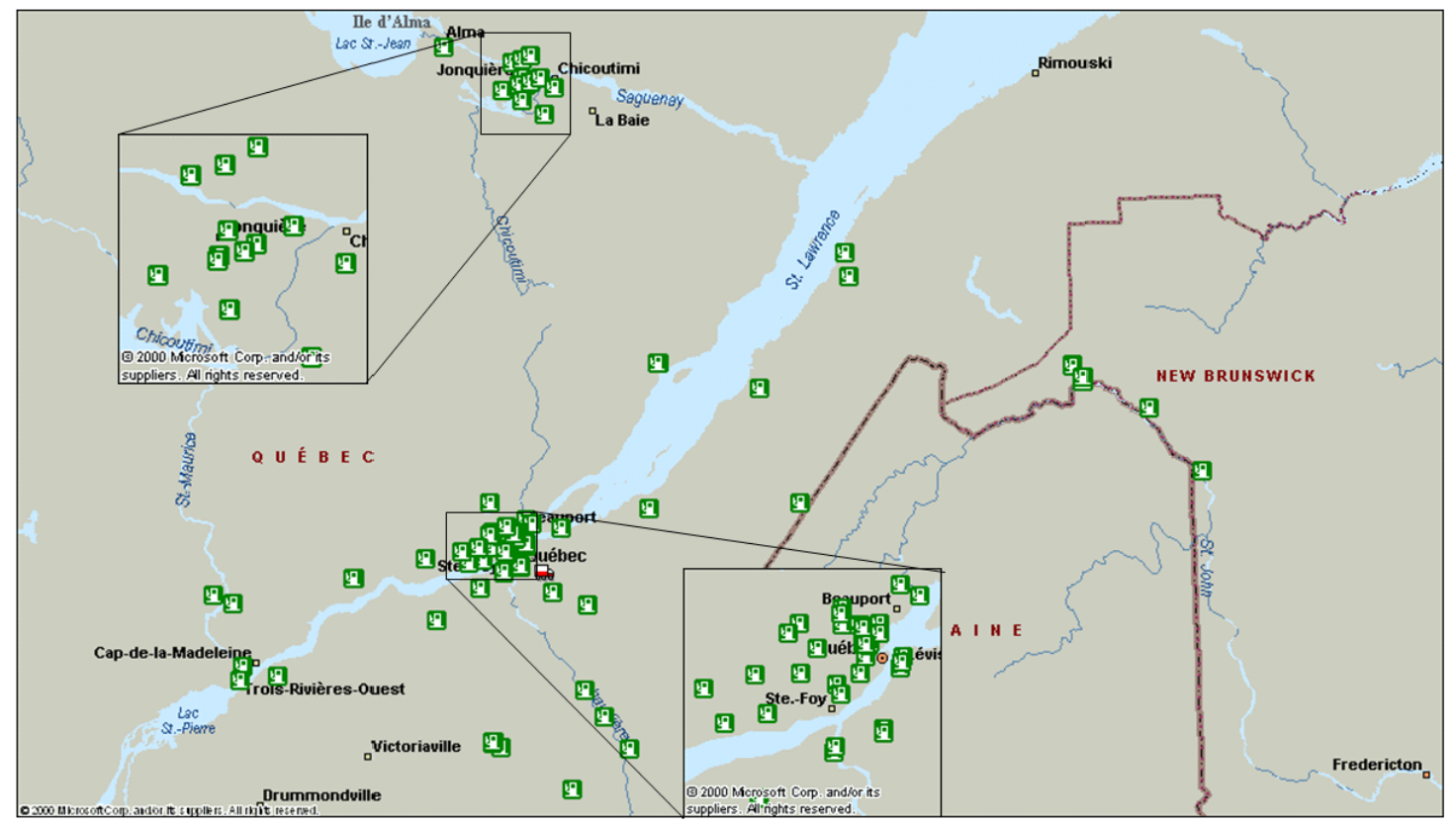

Figure 7: Stations location

Table 9: Results obtained by CPLEX 11.0

\begin{tabular}{|c|c|c|c|c|c|c|}
\hline \multirow[b]{2}{*}{ Scenario } & \multicolumn{3}{|c|}{ Automatic branching } & \multicolumn{3}{|c|}{ Strong branching } \\
\hline & \begin{tabular}{|c}
$\begin{array}{c}\text { Best solution } \\
\text { reached }\end{array}$ \\
\end{tabular} & $\begin{array}{l}\text { Optimality } \\
\text { gap at failure }\end{array}$ & $\begin{array}{l}\text { Time until } \\
\text { failure (sec.) }\end{array}$ & $\begin{array}{l}\text { Best solution } \\
\text { reached }\end{array}$ & $\begin{array}{l}\text { Optimality } \\
\text { gap at failure }\end{array}$ & $\begin{array}{c}\text { Time until } \\
\text { failure (sec.) }\end{array}$ \\
\hline A & 12162 & $0.43 \%$ & 1112 & 12162 & $0.42 \%$ & 16512 \\
\hline $\mathrm{B}$ & 11258 & $0.58 \%$ & 1354 & 11262 & $0.91 \%$ & 19054 \\
\hline $\mathrm{C}$ & 12953 & $0.44 \%$ & 3319 & 12981 & $0.22 \%$ & 16986 \\
\hline $\mathrm{D}$ & 12862 & $0.92 \%$ & 1635 & 12863 & $0.90 \%$ & 11121 \\
\hline
\end{tabular}

Table 10: Solutions obtained by the proposed heuristics*

\begin{tabular}{|c|c|c|c|c|}
\hline \multirow{3}{*}{ Scenario } & \multicolumn{2}{|c|}{ Multi-start local improvement heuristic } & \multirow{2}{*}{$\begin{array}{c}\text { Simulated annealing } \\
\qquad H=6\end{array}$} & \multirow{3}{*}{$\begin{array}{c}\text { Best } \\
\text { CPLEX } \\
\text { solution }\end{array}$} \\
\hline & $P=6$ & $P=10$ & & \\
\hline & $\begin{array}{c}\text { Initial solutions by the } 6 \\
\text { construction heuristics }\end{array}$ & Initial solutions by $C 1 r$ & $R_{\max }=25000$ & \\
\hline A & 12179 & 12162 & 12173 & 12162 \\
\hline $\mathrm{B}$ & 11309 & 11255 & 11314 & 11262 \\
\hline $\mathrm{C}$ & 12944 & 12978 & 12948 & 12981 \\
\hline $\mathrm{D}$ & 12889 & 12918 & 12884 & 12863 \\
\hline Time (sec) & 10.50 & 16.75 & 15.50 & 8886.6 \\
\hline
\end{tabular}

*Boldface figures indicate the best found solution for each scenario

To complete our assessment of the proposed heuristics, we calculated the value of three other criteria that are sometimes monitored in practice. We calculated the quantity of products to be 
delivered, the net revenue per 1000 litres delivered and the maximum overtime hours, for each of the solutions given in Table 10. Table 11 gives the results for scenario A. It shows that solutions with less net revenue have slightly higher values for the quantity of products to deliver. However the difference is quite small and represents $0.003 \%$. In the same time, the solution with the largest net revenue has also the largest net revenue per 1000 litres to deliver. All these solutions have the same value for the maximum, among all trucks, of overtime hours.

Tables 12, 13 and 14 compare these same 4 criteria for scenarios B, C and D respectively. Comparing the results for all 4 scenarios, it seems that solutions with largest or the second largest net revenue have also the largest revenue per 1000 litres. For 3 of these scenarios all solutions have the same maximum overtime hours. The results indicate that in only one case (scenario B), the solution having the largest net revenue also have the largest quantity to deliver.

\section{HOW TO DEAL WITH DISRUPTIONS AND DELAYS}

In real life, disruptions and delays occur and we have to be able to deal with them. Mainly, there are two events that may cause disruptions: vehicles breakdown and drivers absence. Usually, transportation companies are able to replace absent drivers quite quickly and at most at the next day. It is also possible to rent a truck to replace the broken one the next day. Small delays due to small traffic problems are not very important as trip durations include a margin of about $10 \%$. Larger delays may make it impossible to finish the remaining trips as originally planned.

Thus, in case of a sudden disruption like a truck breakdown, we need to update our operations plan by repacking all the remaining (not yet started) trips and assigning them to the remaining vehicles. This can be done very easily using the same solution methods developed in this paper. However, in presenting our methods we implicitly assumed that all trucks are available at the beginning of the planning period and have the same regular and overtime working hours. In updating our plan due to an important disruption, we have to apply our packing heuristics while taking into consideration only the remaining working time for every truck.

For example, if the working day is composed of 10 regular and 5 overtime hours, starts at 7 a.m., and a truck breaks down at 2 p.m. The remaining regular working hours for the other tucks 
is the time from their return to the charging terminal after finishing their current trip and 5 p.m. If a truck returns after 5 p.m., it has no remaining regular hours and the time between its return time and 10 p.m. is its remaining overtime hours.

\section{CONCLUSIONS}

This paper introduced a generalized version of the trip packing problem, gave a mathematical formulation of the problem, developed heuristic solution procedures to solve it and presented a computational experiment to assess the quality of the solutions obtained by these heuristics. The considered problem involves a heterogeneous fleet of tank trucks that should deliver different petrol products to a number of petrol stations using a set of pre-designed trips. But as we have trucks of different configurations and capacities, some trips can not be carried out by some trucks Furthermore, the cost and revenue of each trip depends on the truck to be used.

The problem is shown to be NP-hard and commercial MIP commercial codes are not able to solve problem instances of even medium size to optimality. In addition this may require long computing hours while we need very quick solutions. The heuristics presented in this paper were able to produce very good solutions with little computational time and effort.

To the best of our knowledge, this is the first research work that addressed this new problem. Further research is needed to produce more efficient heuristics and to try to develop optimal solution methods. We are designing some nature-inspired heuristics (see Doerner et al. [24]) to produce heuristic solutions and we are planning to use a Greedy Randomized Adaptive Memory Programming Search like the one used in [25]. Two optimal approaches could be investigated: the Lagrangean decomposition approach inspired by the one used in [26] and the branch-and-cut algorithms. 
Table 11: results corresponding to scenario A (10 regular and 5 overtime hours; $C=30$ )

\begin{tabular}{|c|c|c|c|c|}
\hline \multirow{3}{*}{ Evaluation criterion } & \multicolumn{2}{|c|}{$\begin{array}{l}\text { Multi-start local improvement } \\
\text { heuristic }\end{array}$} & \multirow{2}{*}{$\begin{array}{c}\begin{array}{c}\text { Simulated } \\
\text { annealing }\end{array} \\
H=6\end{array}$} & \multirow{3}{*}{$\begin{array}{c}\text { Best CPLEX } \\
\text { solution }\end{array}$} \\
\hline & $P=6$ & $P=10$ & & \\
\hline & $\begin{array}{c}\text { Initial solutions by the } \\
6 \text { construction } \\
\text { heuristics }\end{array}$ & $\begin{array}{l}\text { Initial solutions by } \\
\qquad C 1 r\end{array}$ & $R_{\max }=25000$ & \\
\hline Net revenue & 12179 & 12162 & 12173 & 12162 \\
\hline Quantity to deliver (litres) & 2755.5 & 2763 & 2764.5 & 2763 \\
\hline Net revenue per 1000 litres & 4.420 & 4.400 & 4.409 & 4.400 \\
\hline Maximum overtime (hrs) & 5 & 5 & 5 & 5 \\
\hline
\end{tabular}

*Boldface figures indicate the best found solution for each scenario

Table 12: results corresponding to scenario B (10 regular and 5 overtime hours; $C=60$ )

\begin{tabular}{|l|c|c|c|c|}
\hline \multirow{2}{*}{ Evaluation criterion } & \multicolumn{2}{|c|}{$\begin{array}{c}\text { Multi-start local improvement } \\
\text { heuristic }\end{array}$} & $\begin{array}{c}\text { Simulated } \\
\text { annealing }\end{array}$ & \multirow{2}{*}{$\begin{array}{c}\text { Best CPLEX } \\
\text { solution }\end{array}$} \\
\cline { 2 - 4 } & $\begin{array}{c}P=6 \\
\begin{array}{c}\text { Initial solutions by the } \\
6 \text { construction } \\
\text { heuristics }\end{array}\end{array}$ & $\begin{array}{c}\text { Initial solutions by } \\
C 1 r\end{array}$ & $R_{\max }=25000$ & \\
\hline Net revenue & 11309 & 11255 & $\mathbf{1 1 3 1 4}$ & 11262 \\
\hline Quantity to deliver (litres) & 2755.5 & 2763 & $\mathbf{2 7 6 4}$ & 2761 \\
\hline Net revenue per 1000 litres & $\mathbf{4 . 1 0 4}$ & 4.073 & 4.093 & 4.079 \\
\hline Maximum overtime (hrs) & 5 & 5 & 5 & 5 \\
\hline
\end{tabular}

Table 13: results corresponding to scenario C (12 regular and 3 overtime hours; $C=30$ )

\begin{tabular}{|l|c|c|c|c|}
\hline \multirow{2}{*}{ Evaluation criterion } & \multicolumn{2}{|c|}{$\begin{array}{c}\text { Multi-start local improvement } \\
\text { heuristic }\end{array}$} & $\begin{array}{c}\text { Simulated } \\
\text { annealing }\end{array}$ & \multirow{2}{*}{$\begin{array}{c}\text { Best CPLEX } \\
\text { solution }\end{array}$} \\
\cline { 2 - 5 } & $\begin{array}{c}P=6 \\
\begin{array}{c}\text { Initial solutions by the } \\
6 \text { construction } \\
\text { heuristics }\end{array}\end{array}$ & $\begin{array}{c}\text { Initial solutions by } \\
C 1 r\end{array}$ & $R_{\text {max }}=25000$ & \\
\hline Net revenue & 12944 & 12978 & 12948 & $\mathbf{1 2 9 8 1}$ \\
\hline Quantity to deliver (litres) & 2754.5 & 2753.5 & $\mathbf{2 7 5 9 . 5}$ & 2753 \\
\hline Net revenue per 1000 litres & 4.699 & 4.713 & 4.692 & $\mathbf{4 . 7 1 5}$ \\
\hline Maximum overtime (hrs) & 3 & 2 & $\mathbf{1}$ & 3 \\
\hline
\end{tabular}

Table 14: results corresponding to scenario D (12 regular and 3 overtime hours; $C=60$ )

\begin{tabular}{|l|c|c|c|c|}
\hline \multirow{2}{*}{ Evaluation criterion } & \multicolumn{2}{|c|}{$\begin{array}{c}\text { Multi-start local improvement } \\
\text { heuristic }\end{array}$} & $\begin{array}{c}\text { Simulated } \\
\text { annealing }\end{array}$ & \multirow{2}{*}{$\begin{array}{c}\text { Best CPLEX } \\
\text { solution }\end{array}$} \\
\cline { 2 - 5 } & $\begin{array}{c}P=6 \\
\begin{array}{c}\text { Initial solutions by the } \\
6 \text { construction } \\
\text { heuristics }\end{array}\end{array}$ & $\begin{array}{c}\text { Initial solutions by } \\
C 1 r\end{array}$ & $R_{\text {max }}=25000$ & \\
\hline Net revenue & 12889 & $\mathbf{1 2 ~ 9 1 8}$ & 12884 & 12863 \\
\hline Quantity to deliver (litres) & 2745 & 2753.5 & 2756.5 & $\mathbf{2 7 6 0}$ \\
\hline Net revenue per 1000 litres & $\mathbf{4 . 6 9 5}$ & 4.691 & 4.674 & 4.660 \\
\hline Maximum overtime (hrs) & 2 & 2 & 2 & 2 \\
\hline
\end{tabular}




\section{References}

[1] Cornillier F, Boctor FF, Renaud J, Laporte G. A heuristic for the multi-period petrol station replenishment problem, European Journal of Operational Research 2008, 191, 295-305.

[2] Brandão J, Mercer A. A tabu search algorithm for the multi-trip vehicle routing and scheduling problem. European Journal of Operational Research 1997; 100: 180-191.

[3] Brandão J, Mercer A. The multi-trip vehicle routing problem. Journal of the Operational Research Society 1998; 49: 799-805.

[4] Fleischmann B. The vehicle routing problem with multiple use of vehicles, working paper, 1990, Fachbereich Wirtschaftswissenschaften, Universität Hamburg.

[5] Taillard E, Laporte G, Gendreau M. Vehicle routing with multiple use of vehicles. Journal of the Operational Research Society 1996; 47: 1065-1070.

[6] Golden B, Laporte G, Taillard E. An adaptive memory heuristic for a class of vehicle routing problems with minmax objective. Computer and Operations Research 1997; 24: 445-452.

[7] Zhao QH, Wang SY, Lai KK, Xia GP. A vehicle routing problem with multiple use of vehicles. Advanced Modeling and Optimization 2002, 4: 21-40.

[8] Petch R, Salhi S. A multi-phase constructive heuristic for the vehicle routing problem with multiple trips. Discrete Applied Mathematics 2004; 133: 69-92.

[9] Olivera A, Viera O. Adaptive memory programming for the vehicle routing problem with multiple trips. Computers \& Operations Research 2007; 34: 28-47.

[10] Coffman E, Garey M, Johnson D. Approximation algorithms for bin packing: A survey. In: Hochbaum D, editor. Approximation algorithms for NP-hard problems, Boston: PWS Publishing; 1996, p. 46-93.

[11] Prins C. Efficient heuristics for the heterogeneous fleet multi-trip VRP with application to a large-scale real case, Journal of Mathematical Modelling and Algorithms 2002; 1: 135-150.

[12] Clarke G, Wright JW. Scheduling of vehicles from a central depot to a number of delivery points, Operations Research 1964, 12: 568-581.

[13] Rochat Y, Taillard E. Probabilistic diversification and intensification in local search for vehicle routing, Journal of Heuristics 1995, 1: 147-167.

[14] Taqa Allah D, Renaud J, Boctor FF. Le problème d'approvisionnement des stations d’essence, Journal Européen des Systèmes Automatisés 2000, 34 : 11-33.

[15] Malépart V, Boctor FF, Renaud J, Labilois S. Nouvelles approches pour l'approvisionnement des stations d'essence. Revue Française de Gestion Industrielle 2003, 22: 15-31.

[16] Cornillier F, Boctor FF, Laporte G, Renaud J. An Exact algorithm for the petrol station replenishment problem, Journal of the Operational Research Society, 2008, 59, 607,615.

[17] Cornillier F, Laporte G, Boctor FF, Renaud J. The petrol station replenishment problem with time windows. Computers and Operations Research, 2009, 36, 919-935. 
[18] Garey MR, Johnson DS. Computers and tractability, New York; W.H. Freeman and Company; 1979.

[19] Sahni S, Gonzalez T, P-complete approximation problems, Journal of the Association of Computing Machinery 1976, 23, 555-565

[20] Boctor FF, Resource-constrained project scheduling by simulated annealing, International Journal of Production Research 1996, 34: 2335-2351.

[21] Jensen R E, A Dynamic programming algorithm for cluster analysis. Journal of the Operations Research Society of America, 1969, 7, 1034-1057.

[22] Hubert L J, Arabie P, Meulman J J. Combinatorial data analysis: Optimization by dynamic programming. Philadelphia, SIAM, 2001.

[23] Van Os B J, Meulman J J. Improving dynamic programming strategies for partitioning. Journal of classification, 2004, 21, 207-230.

[24] Doerner K F,Gutjahr W J, Hartl R F Strauss C, Stummer C. Nature-inspired mataheuristics for multiobjective activity crashing. Omega 2008, 36, 1019-1037.

[25] Yazgı Tütüncü G, Carreto C, Baker B M. A visual interactive approach to classical and mixed vehicle routing problems with backhauls. Omega 2009, 37, 138-154.

[26] Barcia P, Jörnsten K. Improved Lagrangean decomposition: An application to the generalized assignment problem. European Journal of Operational Research1990, 46, 84-92. 
APPENDIX: Data for the 51 routes of the real life instance

\begin{tabular}{|c|c|c|c|c|c|c|c|c|c|c|c|c|}
\hline \multirow{2}{*}{ Route } & \multirow{2}{*}{$\begin{array}{l}\text { Length } \\
(\mathrm{km})\end{array}$} & \multirow{2}{*}{$\begin{array}{l}\text { Duration } \\
\text { (min) }\end{array}$} & \multicolumn{5}{|c|}{ Quantity to deliver by truck type } & \multicolumn{5}{|c|}{ Net revenue for truck type } \\
\hline & & & 1 & 2 & 3 & 4 & 5 & 1 & 2 & 3 & 4 & 5 \\
\hline 1 & 296,6 & 312 & 54 & 59 & 57 & 54 & 54 & 400 & 430 & 418 & 400 & 400 \\
\hline 2 & 292,2 & 308 & 58 & 59 & 58 & 54 & 54 & 419 & 425 & 419 & 396 & 396 \\
\hline 3 & 416,3 & 408 & 58 & 60 & NF & $\mathrm{NF}$ & NF & 563 & 580 & $\mathrm{NF}$ & $\mathrm{NF}$ & $\mathrm{NF}$ \\
\hline 4 & 396,6 & 392 & 42 & 42 & 42 & 42 & 42 & 413 & 413 & 413 & 413 & 413 \\
\hline 5 & 128 & 177 & 31 & 31 & 31 & 31 & 31 & 159 & 159 & 159 & 159 & 159 \\
\hline 6 & 53,4 & 117 & 57.5 & 60 & 60 & NF & NF & 141 & 144 & 144 & $\mathrm{NF}$ & NF \\
\hline 7 & 33,8 & 102 & 46 & 46 & 46 & 46 & 46 & 111 & 111 & 111 & 111 & 111 \\
\hline 8 & 32,1 & 100 & 57 & 60 & 58 & 54 & 54 & 117 & 119 & 117 & 115 & 115 \\
\hline 9 & 51,2 & 115 & $\mathrm{NF}$ & 57 & 55 & 53 & $\mathrm{NF}$ & $\mathrm{NF}$ & 138 & 136 & 134 & $\mathrm{NF}$ \\
\hline 10 & 237,8 & 265 & $\mathrm{NF}$ & 57 & 57 & 54 & $\mathrm{NF}$ & $\mathrm{NF}$ & 351 & 351 & 337 & $\mathrm{NF}$ \\
\hline 11 & 136,8 & 169 & 57 & 57 & 57 & 54 & 54 & 236 & 236 & 236 & 228 & 228 \\
\hline 12 & 149,6 & 194 & 15 & 15 & 15 & 15 & 15 & 125 & 125 & 125 & 125 & 125 \\
\hline 13 & 61,4 & 109 & 58 & 59 & 59 & 54 & 54 & 151 & 152 & 152 & 146 & 146 \\
\hline 14 & 41 & 107 & 58 & 58 & 58 & 54 & $\mathrm{NF}$ & 128 & 128 & 128 & 124 & $\mathrm{NF}$ \\
\hline 15 & 376,9 & 376 & 56.5 & 59 & 59 & 54 & 54 & 506 & 525 & 525 & 487 & 487 \\
\hline 16 & 453,2 & 422 & 58 & 60 & 60 & 54 & 54 & 606 & 624 & 624 & 569 & 569 \\
\hline 17 & 136,8 & 169 & 52 & 52 & 52 & 52 & 52 & 222 & 222 & 222 & 222 & 222 \\
\hline 18 & 136,8 & 169 & 52 & 52 & 52 & 52 & 52 & 222 & 222 & 222 & 222 & 222 \\
\hline 19 & 19,7 & 90 & 57.5 & 60 & 60 & $\mathrm{NF}$ & $\mathrm{NF}$ & 103 & 104 & 104 & $\mathrm{NF}$ & $\mathrm{NF}$ \\
\hline 20 & 99,3 & 154 & 57.5 & 60 & 60 & $\mathrm{NF}$ & $\mathrm{NF}$ & 194 & 199 & 199 & $\mathrm{NF}$ & $\mathrm{NF}$ \\
\hline 21 & 188 & 225 & 55 & 55 & 55 & 54 & 52 & 287 & 287 & 287 & 283 & 276 \\
\hline 22 & 68,8 & 130 & 57 & 57 & 57 & 54 & 54 & 158 & 158 & 158 & 154 & 154 \\
\hline 23 & 99 & 139 & 53 & 53 & 53 & 53 & 52 & 185 & 185 & 185 & 185 & 183 \\
\hline 24 & 149,6 & 194 & 30 & 30 & 30 & 30 & 30 & 170 & 170 & 170 & 170 & 170 \\
\hline 25 & 33,60 & 86 & 55.5 & 56 & 56 & 54 & 53 & 117 & 118 & 118 & 116 & 116 \\
\hline 26 & 48,80 & 114 & 53 & 59 & 59 & 53 & 54 & 132 & 138 & 138 & 132 & 133 \\
\hline 27 & 39,50 & 106 & 32 & 32 & 32 & 32 & 32 & 105 & 105 & 105 & 105 & 105 \\
\hline 28 & 39,40 & 106 & 55 & 55 & 55 & 53 & 53 & 123 & 123 & 123 & 122 & 122 \\
\hline 29 & 35,50 & 103 & 58 & 60 & 60 & 54 & 54 & 121 & 123 & 123 & 118 & 118 \\
\hline 30 & 22,40 & 77 & 58 & 60 & 60 & 54 & 54 & 106 & 107 & 107 & 104 & 104 \\
\hline 31 & 29,80 & 98 & 57.5 & 58 & 58 & 54 & 54 & 114 & 115 & 115 & 112 & 112 \\
\hline 32 & 38,20 & 105 & 58 & 60 & 60 & 54 & 54 & 124 & 126 & 126 & 121 & 121 \\
\hline 33 & 31,60 & 100 & 56 & 56 & 57 & 53 & 54 & 115 & 115 & 116 & 113 & 114 \\
\hline 34 & 9,50 & 82 & 55 & 55 & 56 & 54 & 54 & 90 & 90 & 91 & 90 & 90 \\
\hline 35 & 9,60 & 67 & 55 & 55 & 55 & 54 & 54 & 91 & 91 & 91 & 90 & 90 \\
\hline 36 & 306,00 & 304 & 58 & 58 & 59 & 54 & 54 & 435 & 435 & 441 & 410 & 410 \\
\hline 37 & 288,70 & 305 & 58 & 60 & 60 & 54 & $\mathrm{NF}$ & 415 & 426 & 426 & 392 & $\mathrm{NF}$ \\
\hline 38 & 323,10 & 333 & 58 & 59 & 60 & 54 & $\mathrm{NF}$ & 455 & 461 & 468 & 429 & $\mathrm{NF}$ \\
\hline 39 & 298,60 & 298 & 58 & 59 & 60 & 54 & 54 & 426 & 432 & 438 & 402 & 402 \\
\hline 40 & 291,20 & 307 & 51 & 51 & 51 & 51 & 51 & 377 & 377 & 377 & 377 & 377 \\
\hline 41 & 307,30 & 320 & 56.5 & 59 & 60 & 53 & 54 & 427 & 443 & 449 & 406 & 412 \\
\hline 42 & 831,80 & 740 & 58 & 60 & 58 & 54 & $\mathrm{NF}$ & 1045 & 1078 & 1045 & 978 & $\mathrm{NF}$ \\
\hline 43 & 132,00 & 165 & 56.5 & 59 & 59 & 54 & 54 & 229 & 236 & 236 & 223 & 223 \\
\hline 44 & 151,40 & 196 & 58 & 58 & 59 & 54 & 54 & 256 & 256 & 259 & 244 & 244 \\
\hline 45 & 176,00 & 215 & 54 & 54 & 54 & 53 & 53 & 270 & 270 & 270 & 267 & 267 \\
\hline 46 & 165,60 & 192 & 53 & 53 & 53 & 53 & 53 & 256 & 256 & 256 & 256 & 256 \\
\hline 47 & 174,00 & 199 & 54 & 54 & 54 & 53 & 54 & 268 & 268 & 268 & 264 & 268 \\
\hline 48 & 174,00 & 214 & 54 & 54 & 55 & 52 & 53 & 268 & 268 & 271 & 261 & 264 \\
\hline 49 & 42,80 & 109 & 57 & 57 & 57 & 54 & 53 & 129 & 129 & 129 & 126 & 125 \\
\hline 50 & 53,30 & 117 & 58 & 60 & 60 & 54 & $\mathrm{NF}$ & 142 & 144 & 144 & 138 & $\mathrm{NF}$ \\
\hline 51 & 27,40 & 96 & 54 & 55 & 55 & 53 & 54 & 110 & 110 & 110 & 109 & 110 \\
\hline
\end{tabular}

